\title{
Caracterização química, espectroscópica e microtextural de feldspatos piroexpansíveis para possível aplicação nas indústrias de cerâmica de revestimento e vidreira
}

\section{(Chemical, spectroscopic and microtextural characterization of thermo-expansive feldspar for possible application in ceramic tile and glass industries)}

\author{
G. M. Aarão, R. Scholz \\ Departamento de Geologia, Universidade Federal de Ouro Preto, Campus Morro do Cruzeiro s/n, 3, \\ Ouro Preto, MG, Brasil 5400-000 \\ guilhermeaarao@hotmail.com,r_scholz_br@yahoo.com
}

\begin{abstract}
Resumo
Amostras de feldspatos foram submetidas a ensaios tecnológicos de calcinação, possibilitando avaliar as modificações nas propriedades físicas e químicas desses minerais, identificando eventuais problemas tecnológicos e compreendendo as mudanças que ocorrem na estrutura cristalina durante a calcinação. Amostras de feldspatos provenientes do Pegmatito Córrego Boa Vista, localizado no Distrito Pegmatítico de Conselheiro Pena (MG), foram calcinadas em diferentes temperaturas (1100, 1150,1200 e $1250{ }^{\circ} \mathrm{C}$ ) e posteriormente caracterizadas por microssonda eletrônica, microscopia eletrônica de varredura, espectroscopia no infravermelho, espectroscopia Raman e também por microscopia óptica. Desta forma, foi possível avaliar os feldspatos estudados como matéria-prima para possível ou não aplicação nas indústrias de cerâmica de revestimento e vidreira.
\end{abstract}

Palavras-chave: feldspato, cerâmica, expansão, calcinação.

Abstract

Samples of feldspar were submitted to technological tests of calcination, allowing the assessment of the changes in the physical and chemical properties of these minerals, identifying technological problems, and understanding the changes that occur in crystal structure during the calcination. The feldspar samples from the Pegmatite Córrego Boa Vista, located in the Pegmatite District Conselheiro Pena $(M G)$, were calcined in different temperatures $\left(1100,1150,1200\right.$ and $\left.1250{ }^{\circ} \mathrm{C}\right)$ and subsequently characterized by electron probe microanalysis, scanning electron microscopy, infrared spectroscopy, Raman spectroscopy, and optical microscopy. Therefore, it was possible to evaluate the feldspars studied as raw material for possible applications in ceramic tile and glass industries.

Keywords: feldspar, ceramics, expansion, calcination.

\section{INTRODUÇÃO}

O grupo mineral do feldspato é o mais abundante na natureza, correspondendo a cerca de $60 \%$ da crosta terrestre. São constituídos por silicato de alumínio contendo teores variados de $\mathrm{K}, \mathrm{Na}$, $\mathrm{Ca}$ e raramente $\mathrm{Ba}$ entre os seus membros; podem ser encontrados em rochas ígneas, metamórficas e sedimentares, tendo os pegmatitos graníticos como uma das principais fontes dos minerais deste grupo [1]. O feldspato ocupa importante papel em diversos ramos da indústria, tais como indústria de cerâmicas, vidros, tintas, abrasivos, dentre outros [2]. O principal setor consumidor é a indústria de cerâmicas, onde é usado como fundente, servindo também como cimento para as partículas das diversas substâncias cristalinas e promovedor das reações físico-químicas. Também possui larga utilização na indústria vidreira, onde fornece a alumina, aumentando a aplicabilidade do vidro fundido, auxiliando na estabilidade química e inibindo a devitrificação [3]. Em relação a piroexpansão, o minério feldspático é considerado de boa qualidade quando não ocorre expansão e não há formação de poros por escape de fluidos e voláteis quando submetido à queima, não causando danos à estrutura da cerâmica. Esta expansão ocorre na medida em que a temperatura de aquecimento aumenta e os fluidos vão sendo expulsos do interior do mineral, havendo a degeneração da estrutura cristalina e a geração de material amorfo [1, 4]. Sendo assim, estudos de caracterização química e tecnológica de feldspatos são fundamentais para a correta aplicação nos diversos seguimentos industriais, pois o conhecimento amplo das propriedades do minério feldspático constitui um pilar fundamental para o desenvolvimento de uma mineração adequada desse bem mineral, aproveitando desta forma cada tipo de minério de acordo com seu potencial de uso. 


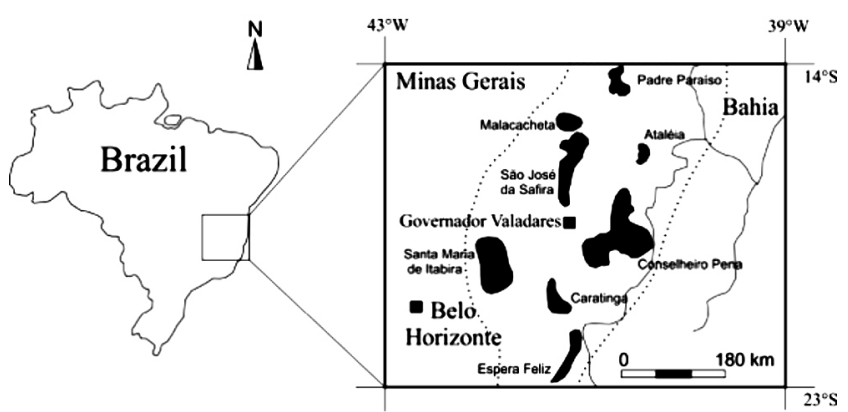

Figura 1: Imagem da localização da Província Pegmatítica Oriental no estado de Minas Gerais (modificado de [6]).

[Figure 1: Image showing location of East Pegmatitic Province in Minas Gerais State (modified from [6]).]

Os feldspatos avaliados no presente estudo são provenientesdoPegmatitoCórregoBoaVista(PCBV), estando localizados no Distrito Pegmatítico de Conselheiro Pena; esta região compreende uma superfície de aproximadamente $3.000 \mathrm{~km}^{2}$ da região leste do estado de Minas Gerais, sendo uma das onze subdivisões metalogenéticas da Província Pegmatítica Oriental do Brasil [5, 6]. Esta província ocupa uma superfície de aproximadamente $80.000 \mathrm{~km}^{2}$ da região leste do estado de Minas Gerais, incluindo parte do sul do estado da Bahia e também do oeste do Espírito Santo (Fig. 1). A Província Pegmatítica Oriental do Brasil está situada na Faixa Araçuaí. Engloba inúmeros corpos pegmatíticos, tanto de origem ígnea, cristalizados a partir de magmas graníticos residuais intrusivos, de idade Brasiliana (450 a $650 \mathrm{Ma}$ ), quanto anatética, os quais possuem mineralogia mais simples e as dimensões são menores, formados a partir da fusão parcial e mobilização de material félsico [5, 7]. A região de estudo está inserida na Folha SE 24-Y-CII - Conselheiro Pena [8], estando localizada na região do Médio Rio Doce, na porção leste do Cráton São Francisco e a centro-leste do Orógeno Araçuaí. Os corpos pegmatitos portadores dos feldspatos avaliados no presente estudo ocorrem principalmente próximo ao granito Urucum [9], pertencente à Suíte G2 [5]. Em geral, encontramse encaixados em biotita xistos da Formação São Tomé, orientados segundo as direções N-S e NE-SW $[10,11]$. Os pegmatitos do campo da Boa Vista localizam-se a $12 \mathrm{~km}$ ao sul da zona urbana de Galileia. Correspondem a um enxame de corpos pegmatíticos que afloram em uma área de $16 \mathrm{~km}^{2}$, com um total de 27 corpos cadastrados. Estes pegmatitos são classificados como da família LCT, classe miarolítico, mineralizados em espodumênio [12]. Caracterizam-se pela abundância em minerais fosfatos, incluindo trifilita-litiofilita como fosfato primário, e uma diversificada associação de minerais secundários. Apresentam-se orientados segundo as direções N-S e NE-SW, subverticais [13].

\section{EXPERIMENTAL}

Primeiramente as amostras foram serradas em quatro corpos de prova com dimensões de aproximadamente $4 \mathrm{~cm}$ x $2 \mathrm{~cm} \times 2 \mathrm{~cm}$, e posteriormente submetidos aos ensaios

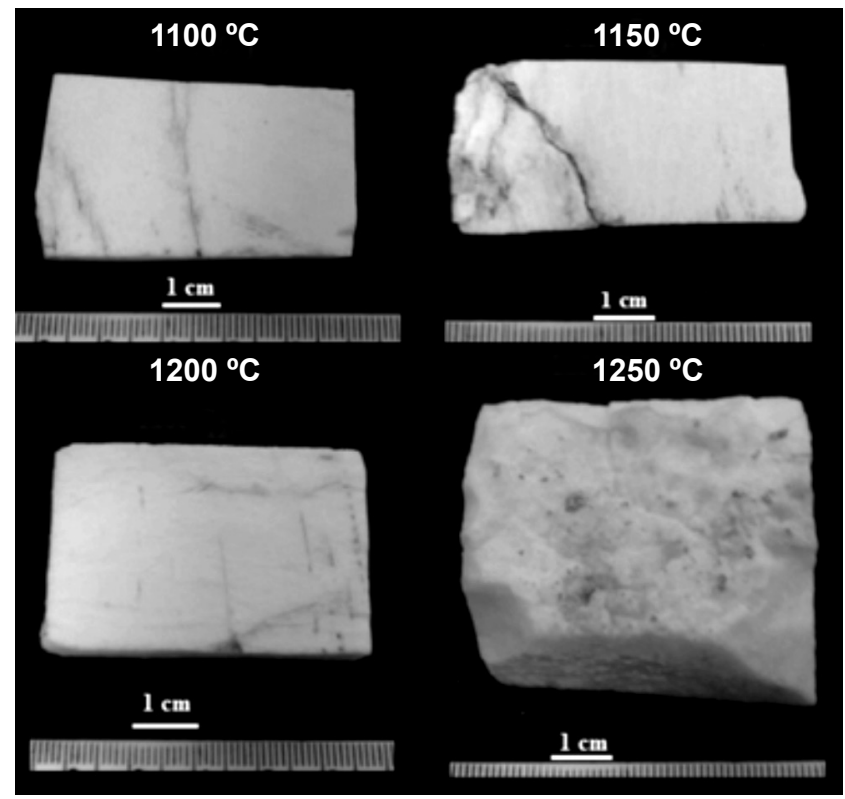

Figura 2: Imagens dos corpos de prova da Lavra do Pegmatito Córrego Boa Vista (PCBV) após sofrer aquecimento em diferentes temperaturas $\left(1100,1150,1200\right.$ e $\left.1250{ }^{\circ} \mathrm{C}\right)$.

[Figure 2: Images of feldspar samples from pegmatite Córrego Boa Vista (PCBV) after calcination at different temperatures (1100, 1150,1200 and $\left.1250^{\circ} \mathrm{C}\right)$.]

de calcinação, sendo realizados em forno tipo mufla Grion TH-92 DP. Os ensaios foram realizados a 1100, 1150, 1200 e $1250^{\circ} \mathrm{C}$ (Fig. 2). Para as amostras que foram calcinadas a $1100^{\circ} \mathrm{C}$, o tempo de queima gasto para o forno alcançar esta temperatura foi de $4 \mathrm{~h}$ e $40 \mathrm{~min}$ a uma taxa de $3,92^{\circ} \mathrm{C} / \mathrm{min}$, mantendo-se a $1100^{\circ} \mathrm{C}$ durante $2 \mathrm{~h}$. O mesmo procedimento foi adotado para os corpos de prova queimados nas demais temperaturas. O tempo de resfriamento foi de $12 \mathrm{~h}$.

Para microscopia eletrônica de varredura (MEV/EDS), fragmentos de aproximadamente $0,25 \mathrm{~cm}^{3}$ de feldspatos calcinados foram montados em stubs de cobre e recobertos com carbono em evaporadora. $\mathrm{O}$ equipamento utilizado foi um microscópio Jeol JSM-5510, apresentando ampliação e resolução de até $300.000 \mathrm{x}$, voltagem variando entre $0,5 \mathrm{a}$ $30 \mathrm{kV}$. Em relação às análises por microssonda eletrônica (EPMA-WDS), fragmentos de aproximadamente $0,25 \mathrm{~cm}^{3}$ de amostras dos feldspatos calcinados foram montadas com embutimento de resina epoxy, sendo polidas com pasta diamantada e posteriormente analisadas quimicamente. $\mathrm{O}$ equipamento utilizado foi um Jeol-JXA-8900R, equipado com 4 espectrômetros WDS (wavelength dispersive spectrometer), utilizando aceleração de voltagem de $20 \mathrm{kV}$ e corrente de feixe de $20 \mathrm{nA}$. Foram utilizados os seguintes padrões de calibração: Al - coríndon, $\mathrm{K}$ - microclínio, $\mathrm{Na}$ Ab100, Si - microclínio, Fe - hematita, Ca - An100; e Mg - $\mathrm{MgO}$ sintético.

As análises microscópicas das lâminas delgadas foram descritas a partir de um microscópio petrográfico Carl Zeiss, Ortholux; as imagens das lâminas foram obtidas em um equipamento de captura constituído por uma câmera digital Interface Sony DFWSX910, acoplada ao microscópio Leica 
HC L3TP. Para a espectroscopia Raman e infravermelho por transformada de Fourier foram utilizadas amostras pulverizadas inseridas em tubo capilar. O equipamento que foi utilizado para a espectroscopia Raman foi um microscópio Olympus BHSM, possuindo objetivas de aumento de 10 x, 20 x e 50 x. Este microscópio faz parte de um sistema do microscópio Raman Renishaw 1000, que também inclui um monocromador, um sistema de filtro e um detector de CCD (1024 pixels). Para a espectroscopia no infravermelho por transformada de Fourier (FTIR), o equipamento utilizado foi um espectrômetro infravermelho Thermo Nicolet 6700 . A técnica adotada foi a de reflectância difusa. Os espectros foram obtidos na região de 400 a 4000 $\mathrm{cm}^{-1}$ com uma resolução de $4 \mathrm{~cm}^{-1}$ e número de varreduras individuais de 200 vezes com supressão de $\mathrm{H}_{2} \mathrm{O}$ e $\mathrm{CO}_{2}$.

\section{RESULTADOS E DISCUSSÃO}

\section{Microscopia óptica}

Através das análises por microscopia óptica, pode-se observar que com o aumento na temperatura de calcinação ocorrem mudanças significativas na textura das amostras, surgindo uma tendência das barras de albita tornaremse descontínuas, estreitas e começarem a se fundir, aumentando concomitantemente o fraturamento na matriz potássica (Figs. 3-I e 3-II). É possível observar que nas temperaturas de 1200 e $1250{ }^{\circ} \mathrm{C}$ ocorrem o surgimento de uma intensa quantidade de bolhas, juntamente com a vitrificação total e o desaparecimento das fases cristalinas (Figs. 3-III e 3-IV).
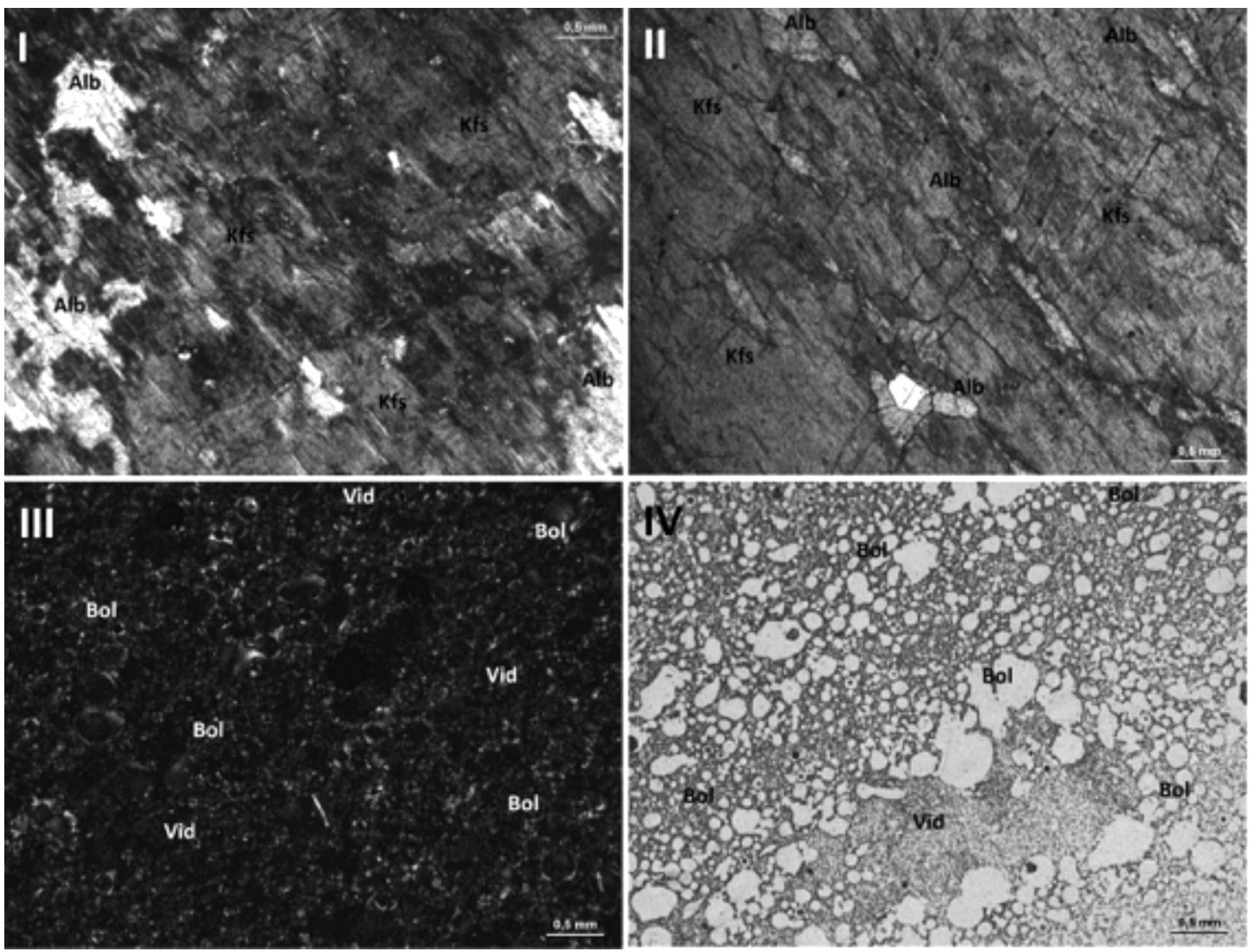

Figura 3: Fotomicrografias (imagens em luz polarizada) das amostras PCBV calcinadas a: (I) $1100{ }^{\circ} \mathrm{C}$, apresentando pequenas fraturas ao longo do plano de clivagem; (II) $1150{ }^{\circ} \mathrm{C}$, apresentando aumento nas fraturas e estreitamento das barras de albita; (III) $1200{ }^{\circ} \mathrm{C}$, apresentando intensa formação de bolhas, vitrificação e desaparecimento das fases cristalinas; e (IV) $1250{ }^{\circ} \mathrm{C}$, apresentando intensa formação de bolhas, vitrificação e desaparecimento das fases cristalinas.

[Figure 3: Photomicrographs (images obtained with polarized light) of the samples $P C B V$ calcined at: (I) $1100^{\circ} \mathrm{C}$, showing small fractures along the cleavage plane; (II) $1150{ }^{\circ} \mathrm{C}$, showing an increase in fractures and narrowing of albite bars; (III) $1200{ }^{\circ} \mathrm{C}$, showing intense blistering, glazing and disappearance of crystalline phases; and (IV) $1250{ }^{\circ} \mathrm{C}$, showing intense blistering, glazing and disappearance of crystalline phases.] 
Microscopia eletrônica de varredura (MEV/EDS)

Através das análises por microscopia eletrônica foi possível obter uma melhor observação microscópica das mudanças ocorridas na textura das amostras após calcinação. A partir das fotomicrografias pôde-se observar que de uma maneira geral os corpos de prova que foram aquecidos a 1100 e $1150^{\circ} \mathrm{C}$ não apresentaram mudanças muito significativas na textura, porém é possível observar a abertura das clivagens, surgimento de algumas fraturas e o aparecimento de raras bolhas. Porém, para as amostras que foram calcinadas a $1200{ }^{\circ} \mathrm{C}$, a clivagem fica mais pronunciada, juntamente com o surgimento de novas bolhas e fraturas. Entretanto, para as amostras que foram submetidas a $1250{ }^{\circ} \mathrm{C}$, de uma maneira geral houve drásticas mudanças na textura do material, passando a apresentar uma textura esponjosa. A Fig. 4 ilustra todas as modificações ocorridas progressivamente com o aumento da temperatura de calcinação.

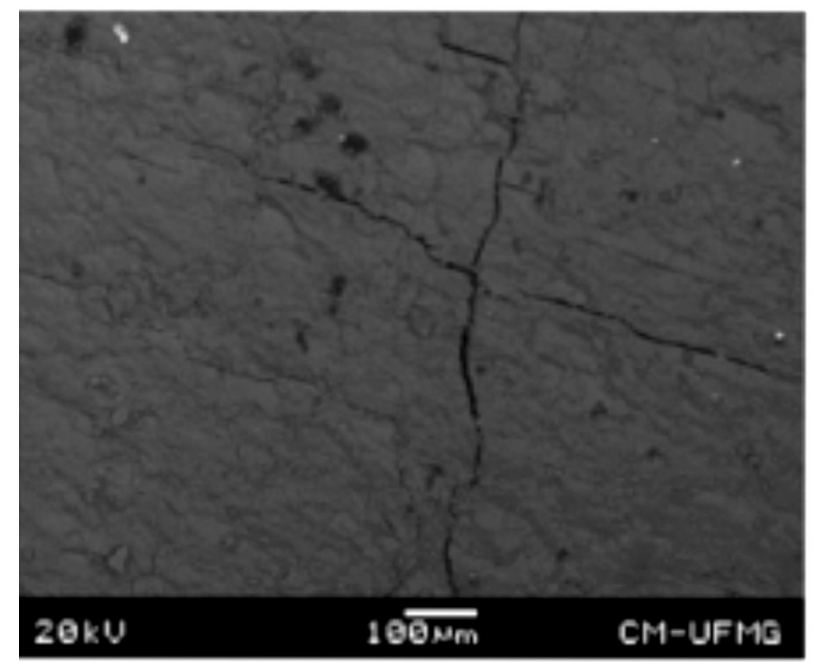

a) $1100^{\circ} \mathrm{C}$

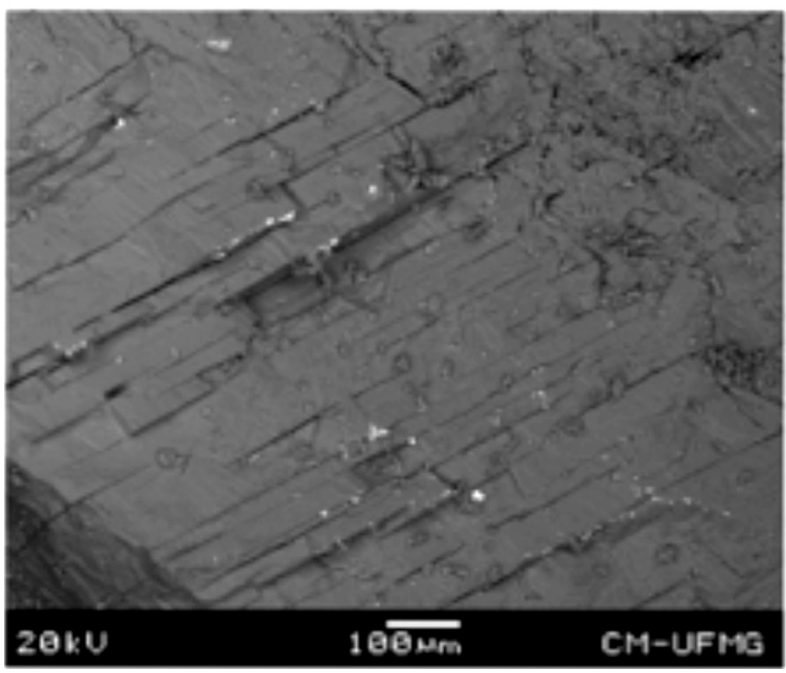

c)

$1200^{\circ} \mathrm{C}$
É importante ressaltar que estas amostras que apresentaram fortes mudanças na textura (formação de bolhas) foram as mesmas que apresentaram maior expansão (Tabela I). O comportamento dos feldspatos amostrados quanto à expansão durante a queima também é ilustrado no diagrama da Fig. 5; neste é relacionado a temperatura de queima com o volume dos corpos de prova obtidos a partir das dimensões antes e após a queima, sendo possível observar que o volume aumenta exponencialmente em função da temperatura de queima.

As densidades relativas e as massas dos corpos de prova estudados mostraram uma crescente diminuição com o aumento da temperatura de queima, apresentando este comportamento de uma forma excessiva na calcinação a $1250^{\circ} \mathrm{C}$ (Tabela II). A partir dos valores obtidos, foi possível a obtenção de um diagrama relacionando a temperatura com a densidade relativa dos corpos de prova (Fig. 6); neste é possível visualizar nitidamente esta tendência, devido à
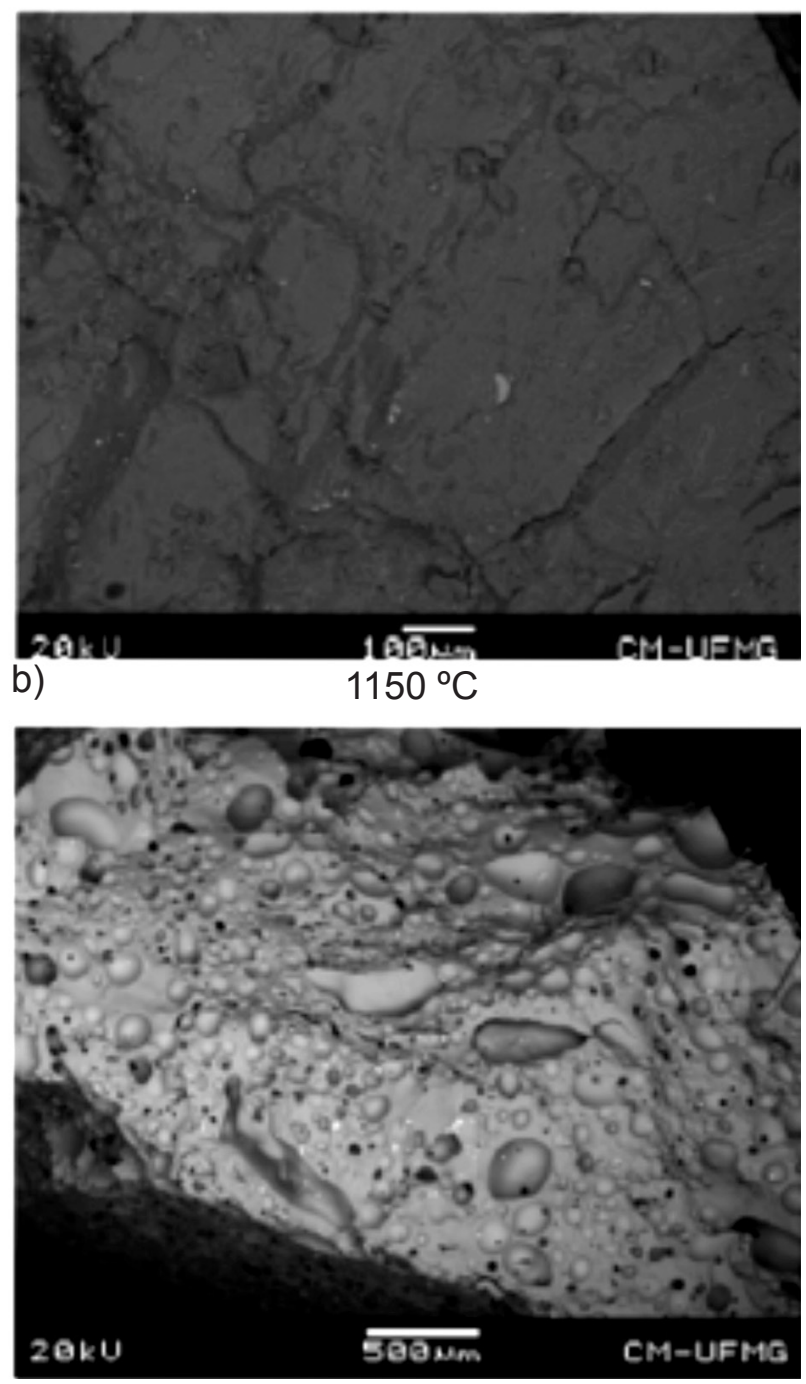

d)

Figura 4: Imagens de elétrons retroespalhados (MEV) das amostras dos corpos de prova calcinados em diferentes temperaturas.

[Figure 4: Backscattering electron images (SEM) of the samples of the specimens calcined at different temperatures.] 
Tabela I - Medições e variações das dimensões (comprimento, altura e largura) dos corpos de prova antes e após a queima. [Table I - Measurements and variations of dimensions (length, height and width) of the samples before and after firing.]

\begin{tabular}{ccccccc}
\hline Amostra & $\begin{array}{c}\text { Temperatura } \\
\left({ }^{\circ} \mathrm{C}\right)\end{array}$ & $\begin{array}{c}\text { Dimensões pré- } \\
\text { queima }\left(\mathrm{cm}^{3}\right)\end{array}$ & $\begin{array}{c}\text { Volume pré- } \\
\text { queima }\left(\mathrm{cm}^{3}\right)\end{array}$ & $\begin{array}{c}\text { Dimensões pós- } \\
\text { queima }\left(\mathrm{cm}^{3}\right)\end{array}$ & $\begin{array}{c}\text { Volume pós- } \\
\text { queima }\left(\mathrm{cm}^{3}\right)\end{array}$ & $\begin{array}{c}\text { Variação de } \\
\text { volume }(\%)\end{array}$ \\
\hline PCBV & 1100 & $4,53 \times 2,44 \times 2,50$ & 27,63 & $4,57 \times 2,45 \times 2,52$ & 28,21 & 2,10 \\
PCBV & 1150 & $4,65 \times 2,31 \times 2,45$ & 26,31 & $4,74 \times 2,35 \times 2,46$ & 27,40 & 4,14 \\
PCBV & 1200 & $4,75 \times 2,34 \times 2,85$ & 31,68 & $4,83 \times 2,45 \times 3,02$ & 35,74 & 12,82 \\
PCBV & 1250 & $4,78 \times 2,27 \times 2,60$ & 28,21 & $5,02 \times 2,48 \times 4,23$ & 52,66 & 86,67 \\
\hline
\end{tabular}

Tabela II - Medições das massas e densidades dos corpos de prova antes e após a queima.

[Table II - Measurements of the masses and densities of the samples before and after firing.]

\begin{tabular}{|c|c|c|c|c|c|c|c|}
\hline Amostra & $\begin{array}{c}\text { Temperatura } \\
\left({ }^{\circ} \mathrm{C}\right)\end{array}$ & $\begin{array}{l}\text { Massa pré- } \\
\text { queima (g) }\end{array}$ & $\begin{array}{l}\text { Massa pós- } \\
\text { queima (g) }\end{array}$ & $\begin{array}{l}\text { Variação da } \\
\text { massa (\%) }\end{array}$ & $\begin{array}{l}\text { Densidade pré- } \\
\text { queima }\left(\mathrm{g} / \mathrm{cm}^{3}\right)\end{array}$ & $\begin{array}{l}\text { Densidade pós- } \\
\text { queima }\left(\mathrm{g} / \mathrm{cm}^{3}\right)\end{array}$ & $\begin{array}{c}\text { Variação da } \\
\text { densidade (\%) }\end{array}$ \\
\hline PCBV & 1100 & 29,44 & 29,19 & 0,85 & 2,59 & 2,44 & 5,79 \\
\hline PCBV & 1150 & 28,42 & 28,11 & 1,09 & 2,53 & 2,40 & 5,14 \\
\hline PCBV & 1200 & 30,15 & 29,44 & 2,35 & 2,55 & 1,73 & 32,16 \\
\hline PCBV & 1250 & 29,44 & 28,46 & 3,33 & 2,52 & 1,15 & 54,37 \\
\hline
\end{tabular}

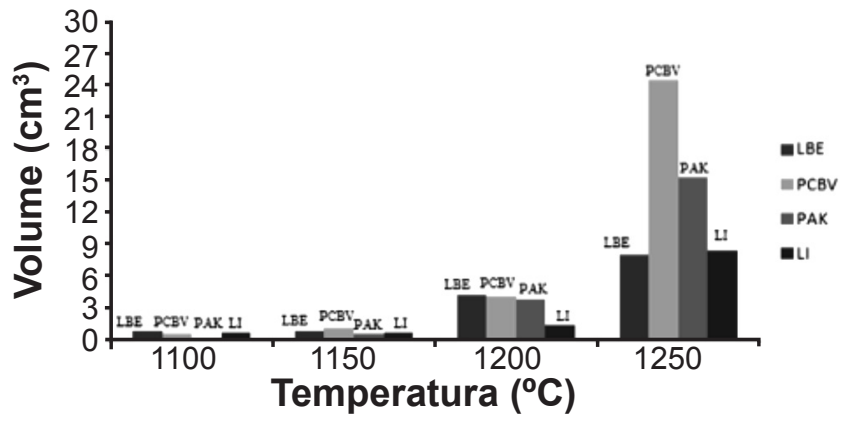

Figura 5: Relação entre a variação de volume com a temperatura de queima exibida pelos corpos de prova.

[Figure 5: Relation between the volume changes with firing temperature exhibited by samples.]

geração de elementos voláteis formadores das bolhas.

\section{Microssonda eletrônica}

Através das análises pontuais por microssonda eletrônica foi possível obter a concentração química percentual dos elementos principais das amostras estudadas, sendo analisados 4 pontos diferentes para cada amostra calcinada nas diferentes faixas de temperatura (Tabela III). Os resultados mostrados a partir da calcinação a $1200{ }^{\circ} \mathrm{C}$ apresentaram variações significativas, pois foi possível observar que a concentração de $\mathrm{Al}_{2} \mathrm{O}_{3}$ aumentou nitidamente após a queima concomitantemente com a diminuição de $\mathrm{Na}_{2} \mathrm{O}$, porém $\mathrm{K}_{2} \mathrm{O}$ e $\mathrm{SiO}_{2}$ não apresentaram variações muito significativas. A variação na composição química ocorre devido à fusão da fase rica em Na (albita na forma de pertita), que atua como fundente. Como resíduo da fusão, são preservadas as fases de mais alta temperatura, como o microclínio. É importante

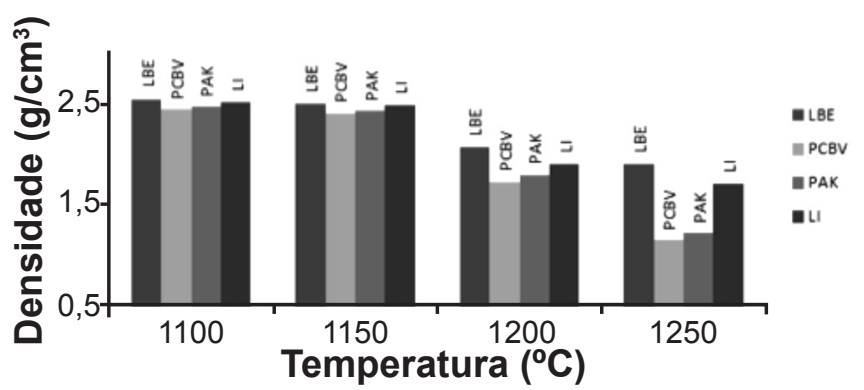

Figura 6: Relação entre a densidade relativa com a temperatura de queima dos corpos de prova.

[Figure 6: Relationship between relative density with the firing temperature of the samples.]

observar que em uma das análises pontuais na amostra PCBV calcinada a $1150{ }^{\circ} \mathrm{C}$ houve um valor discrepante em relação à razão $\mathrm{K}_{2} \mathrm{O} / \mathrm{Na}_{2} \mathrm{O}$, pois apresentou baixo teor de $\mathrm{K}_{2} \mathrm{O}$ e teor muito elevado de $\mathrm{Na}_{2} \mathrm{O}$; isto é devido ao fato que possivelmente o ponto escolhido para a análise química estava inserido na fase albítica do feldspato pertítico.

Sobre a questão de parâmetros químicos para aplicação industrial, em relação ao teor de $\mathrm{Al}_{2} \mathrm{O}_{3}$, as amostras apresentaram valores superiores a $18 \%$, o que as classifica como aptas para uso em cerâmica de revestimento [1, 4]. Não foi detectada presença de ferro nas análises, sendo um importante fator para a indústria de cerâmicas, proporcionando maior alvura deixando a massa mais clara. $\mathrm{O}$ teor de $\mathrm{K}_{2} \mathrm{O}$ nas amostras varia de 13,15 a $13,82 \%$, o que as classifica também para cerâmica de primeira qualidade, onde o valor mínimo exigido é de $12 \%[1,4]$. Para os teores de $\mathrm{Na}_{2} \mathrm{O}$, todas as amostras calcinadas até $1150{ }^{\circ} \mathrm{C}$ estão dentro da margem de teor aceitável (2,0 a 2,5\%). A sílica 
Tabela III - Análise química por microssonda eletrônica nas amostras PCBV aquecidas em temperaturas diferentes (\% em massa). [Table III - Chemical analysis by electron microprobe in samples PCBV heated at different temperatures (wt\%).]

\begin{tabular}{ccccccccc}
\hline Temperatura $\left({ }^{\circ} \mathrm{C}\right)$ & $\mathrm{Al}_{2} \mathrm{O}_{3}$ & $\mathrm{~K}_{2} \mathrm{O}$ & $\mathrm{Na}_{2} \mathrm{O}$ & $\mathrm{SiO}_{2}$ & $\mathrm{FeO}$ & $\mathrm{MgO}$ & $\mathrm{CaO}$ & Total \\
\hline 1100 & 18,84 & 13,65 & 2,42 & 65,23 & 0,01 & 0,02 & 0,10 & 100,27 \\
1100 & 18,91 & 13,44 & 2,15 & 65,44 & 0 & 0,01 & 0,03 & 99,98 \\
1100 & 18,78 & 13,76 & 2,33 & 65,32 & 0,03 & 0 & 0,01 & 100,23 \\
1100 & 18,93 & 13,54 & 2,48 & 65,37 & 0 & 0,01 & 0 & 100,33 \\
Média a 1100 & 18,64 & 13,60 & 2,35 & 65,34 & 0,01 & 0,01 & 0,01 & 100,20 \\
1150 & 18,67 & 13,82 & 2,09 & 65,15 & 0,03 & 0 & 0,04 & 99,80 \\
1150 & 18,66 & 13,54 & 2,37 & 65,38 & 0 & 0 & 0,03 & 99,98 \\
1150 & 18,79 & 13,49 & 2,03 & 65,29 & 0,03 & 0 & 0,01 & 99,64 \\
Média a 1150 & 18,71 & 13,62 & 2,16 & 65,27 & 0,02 & 0,00 & 0,03 & 99,81 \\
1200 & 19,44 & 13,44 & 1,88 & 64,89 & 0 & 0,03 & 0 & 99,68 \\
1200 & 19,77 & 13,28 & 1,93 & 64,91 & 0,01 & 0,03 & 0,05 & 99,98 \\
1200 & 19,46 & 13,63 & 1,77 & 65,03 & 0,02 & 0,01 & 0,02 & 99,94 \\
1200 & 19,54 & 13,37 & 1,84 & 65,07 & 0 & 0,01 & 0,01 & 99,84 \\
Média a 1200 & 19,55 & 13,43 & 1,86 & 64,98 & 0,01 & 0,02 & 0,02 & 99,86 \\
1250 & 20,49 & 13,15 & 1,54 & 64,89 & 0 & 0 & 0,05 & 100,12 \\
1250 & 19,82 & 13,23 & 1,78 & 64,87 & 0 & 0,03 & 0,11 & 99,84 \\
1250 & 20,44 & 13,41 & 1,69 & 64,07 & 0 & 0 & 0,03 & 100,27 \\
1250 & 20,61 & 13,17 & 1,65 & 64,81 & 0 & 0 & 0,05 & 100,29 \\
Média a 1250 & 20,34 & 13,24 & 1,67 & 64,66 & 0,00 & 0,01 & 0,06 & 100,13 \\
\hline
\end{tabular}

Número de onda $\left(\mathrm{cm}^{-1}\right)$

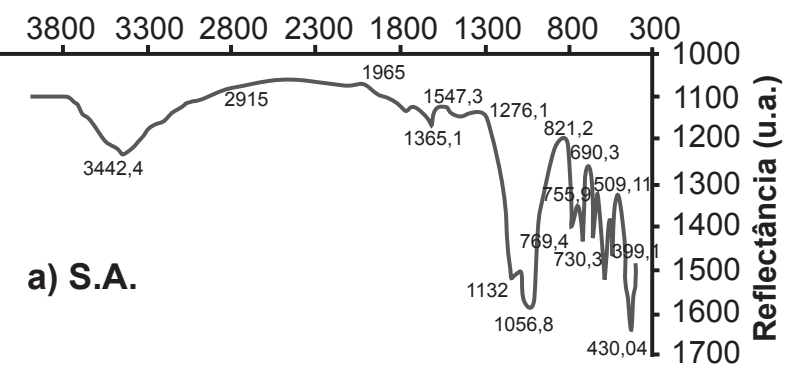

Número de onda $\left(\mathrm{cm}^{-1}\right)$

$390034002900240019001400900 \quad 400$

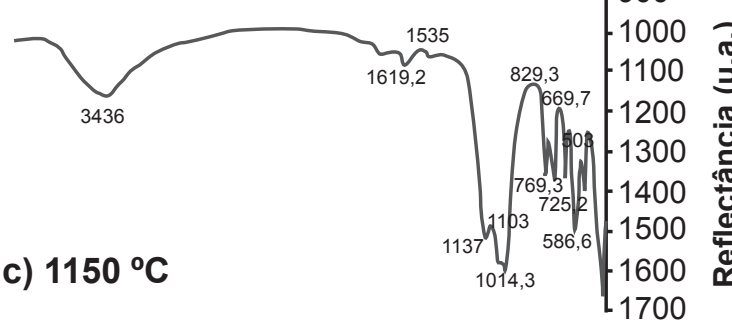

Número de onda $\left(\mathrm{cm}^{-1}\right)$

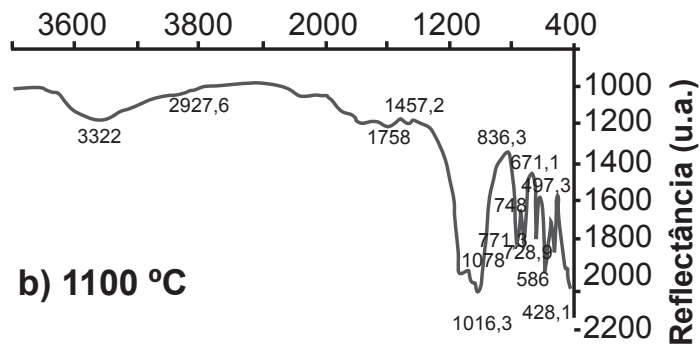

Número de onda $\left(\mathrm{cm}^{-1}\right)$

2200200018001600140012001000400

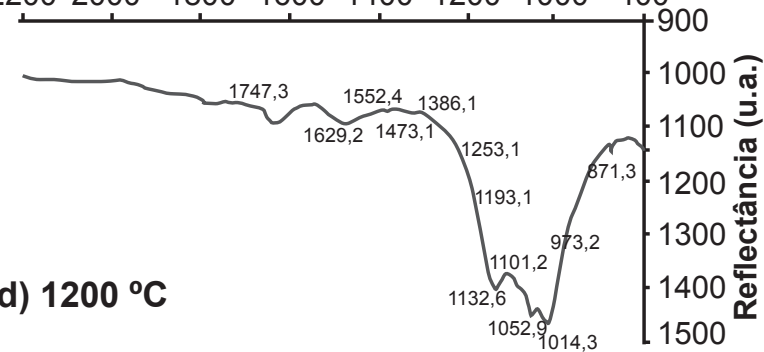

Número de onda $\left(\mathrm{cm}^{-1}\right)$

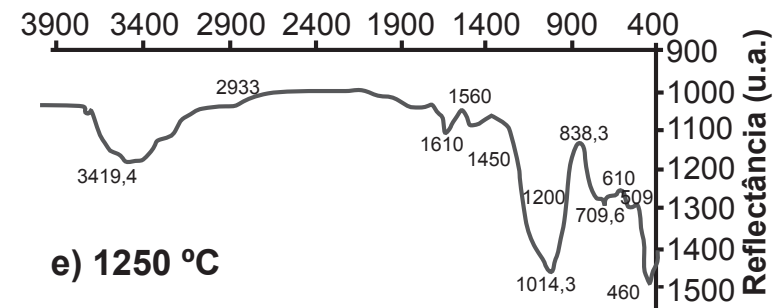

Figura 7: Espectros no infravermelho da amostra PCBV sem sofrer aquecimento (S.A.) e após aquecimento em diferentes temperaturas. [Figure 7: Infrared spectra of the sample PCBV without heating (S.A.) and post-heated at different temperatures.] 

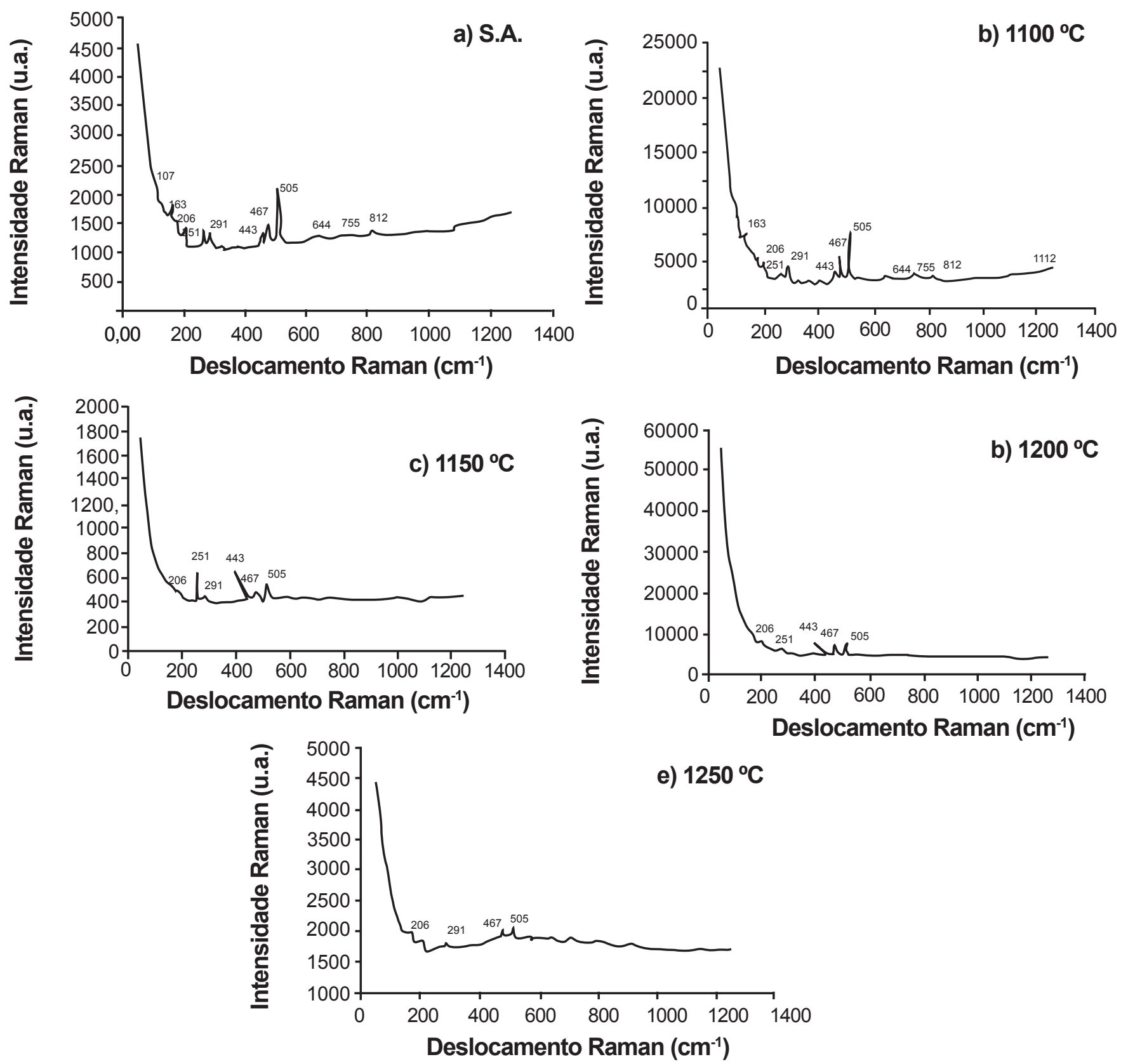

Figura 8: Espectros Raman da amostra PCBV sem sofrer aquecimento (S.A.) e após aquecimento em diferentes temperaturas.

[Figure 8: Raman spectra of the sample PCBV without heating (S.A.) and post-heated at different temperatures.]

apresentou teor médio coerente (64 a $65 \%$ ) estando abaixo do limite máximo de $67 \%$.

\section{Espectroscopia no infravermelho}

Em relação à espectroscopia no infravermelho por transformada de Fourier (FTIR), foram obtidos espectros das amostras no estado natural (sem aquecimento - S.A) e nas demais amostras calcinadas em diferentes temperaturas. O objetivo da aplicação desta técnica no presente estudo foi avaliar a destruição da estrutura cristalina do feldspato durante o processo de calcinação, observando os rompimentos das ligações químicas Si-O, Si-O-Al e O-Si-O. A Fig. 7 apresenta os espectros obtidos; desta forma, foi possível ter uma visão global do feldspato estudado quanto ao comportamento vibracional das moléculas, bem como a degeneração da estrutura cristalina devido ao desaparecimento das ligações $\mathrm{Al}-\mathrm{O}$ e $\mathrm{Si}-\mathrm{O}$, as quais ocorrem de maneira progressiva em relação ao aumento da temperatura de calcinação. A partir da queima realizada a $1150{ }^{\circ} \mathrm{C}$ começa a ocorrer a ausência dos picos principais em relação às ligações $\mathrm{AlO}_{4}$ (espectros entre 700 e $800 \mathrm{~cm}^{-1}$ ), indicando desta forma o desaparecimento progressivo destas ligações de acordo com o aumento da temperatura de queima. Isso ocorre devido à quebra das ligações químicas, transformando a estrutura cristalina do feldspato em material amorfo. Em relação ao comportamento das ligações de $\mathrm{SiO}_{2}$ (bandas entre 1000 e $1200 \mathrm{~cm}^{-1}$ ), também é nítido observar que com o aumento da 
temperatura ocorre a diminuição das vibrações Si-O, porém esta mudança torna-se mais acentuada na temperatura de queima de $1200{ }^{\circ} \mathrm{C}$, indicando a deterioração da estrutura cristalina durante o processo de vitrificação.

\section{Espectroscopia Raman}

Em relação à espectroscopia Raman, novamente foram abordados os espectros obtidos da amostra PCBV no estado natural (sem aquecimento - S.A) e nas demais amostras calcinadas em diferentes temperaturas. Nos espectros (Fig. 8) é possível observar que a partir da queima de $1150{ }^{\circ} \mathrm{C}$ a intensidade dos picos fica menos intensa juntamente com a ausência de alguns picos visualizados nas amostras calcinadas em temperaturas inferiores a $1150{ }^{\circ} \mathrm{C}$. Em 1250 ${ }^{\circ} \mathrm{C}$ ocorre ausência de quase todos os picos, restando os dois picos principais do microclínio, porém em intensidade muito baixa. Desta forma, é possível notar que ocorre o desaparecimento progressivo das ligações químicas nos tetraedros de $\mathrm{SiO}_{4}^{4-}$, principalmente a partir da temperatura de $1150{ }^{\circ} \mathrm{C}$. As análises por espectroscopia Raman mostram que a estrutura cristalina do microclínio é mais estável que de outros componentes, como albita.

\section{CONCLUSÕES}

Os feldspatos estudados apresentaram resultados variados em relação a alguns parâmetros e especificações para possível aplicação industrial. Apesar dos valores das análises químicas por microssonda eletrônica estarem de acordo com as especificações de cerâmica de primeira qualidade, as amostras estudadas não podem ser aplicadas neste segmento, pois apresentaram elevada taxa de expansão durante o aquecimento (piroexpansão) e em alguns casos chegaram a apresentar variação no volume em $86,7 \%$. Esta expansão elevada é devido ao fato de que as amostras de feldspatos avaliadas no presente estudo apresentam grande quantidade de albita, fato comprovado pela presença de estrutura pertítica no microclínio, como observado por microscopia óptica. A presença de albita também foi observada nas análises químicas por microssonda eletrônica, onde algumas regiões apresentam elevado teor em $\mathrm{Na}_{2} \mathrm{O}$. O feldspato sódico apresenta grande fusibilidade em baixas temperaturas (aproximadamente $1120{ }^{\circ} \mathrm{C}$ ) juntamente com baixa viscosidade, sendo assim, na indústria cerâmica de revestimento o feldspato sódico é mais propenso à formação de peças empenadas ou deformadas. As mudanças texturais observadas nas lâminas delgadas e nas micrografias (MEV) mostram intensa formação de bolhas nas amostras calcinadas nas temperaturas mais elevadas; estas bolhas são altamente prejudiciais para o produto cerâmico, pois reduzem a resistência do produto provocando uma textura vesicular sem estética, com baixa qualidade e sem valor de mercado, deformando os moldes e formas, gerando prejuízos na linha de produção. Este aspecto de alteração da textura das amostras coincide com o estado de vitrificação total do material observado nos estudos de espectroscopia no infravermelho e Raman, uma vez que vai ocorrendo o desaparecimento progressivo dos picos principais indicando os rompimentos das ligações dos tetraedros $\mathrm{de} \mathrm{SiO}_{4}{ }^{4-}$ bem como a crescente degeneração da estrutura cristalina dos minerais. Portanto, os feldspatos provenientes do Pegmatito Córrego Boa Vista são altamente piroexpansíveis, tendo seu uso incompatível para aplicação na indústria cerâmica, porém, por possuírem estrutura mais leve, além de poderem ser aplicados na indústria vidreira, podem também ser utilizados em alguns outros segmentos, tais como revestimentos, placas de isolamento térmico, agregados leves, forros de telhados, etc. Outra possível aplicação seria para blendagem com feldspatos de mais alta qualidade, podendo desta forma ser aplicados na indústria cerâmica.

\section{AGRADECIMENTOS}

À Fundação de Amparo à Pesquisa do Estado de Minas Gerais (FAPEMIG) pelo financiamento ao Projeto "Potencial mineral dos pegmatitos do Distrito de Conselheiro Pena, Minas Gerais: caracterização de minerais industriais e aproveitamento de rejeitos", e à Universidade Federal de Ouro Preto (UFOP) e Universidade Federal de Minas Gerais (UFMG) por disponibilizar toda a estrutura necessária para realização dos ensaios laboratoriais. R. Scholz agradece à PROPP/UFOP Edital 2015.

\section{REFERÊNCIAS}

[I] S.T.P. Tavares, C. Castañeda, A.C. Pedrosa-Soares, Cerâm. Ind. 10, 4 (2005) 22.

[2] M. Agus, R. Angius, M. Ghiani, R. Peretti, A. Serci, A. Zucca, Developments in Mineral Processing, $1^{\text {a }}$ Ed., P. Massacci, Roma, Itália (2000) 17.

[3] E. Bernado, J. Doyle, S. Hampshire, Ceram. Int. 34 (2008) 2037.

[4] F.A.N. Oliveira, "Estudo do processo de piroexpansão de feldspatos pegmatíticos e caracterização tecnológica do feldspato potássico", Tese Dr., Instituto de Geociências, Universidade Federal de Minas Gerais, Belo Horizonte, MG, Brasil (2001) 28.

[5] C. Castañeda, J.E. Addad, A. Liccardo, Gemas de Minas Gerais, $1^{\text {a }}$ Ed., Sociedade Brasileira de Geologia, Belo Horizonte (2001) 16.

[6] A.C. Pedrosa-Soares, C.M. Noce, C.M. Wiedemann, C.P. Pinto, Precambrian Res. 110 (2001) 307.

[7] J.M. Correia-Neves, A.C. Pedrosa-Soares, V.R.P.R.O. Marciano, Rev. Bras. Geociências 16, 1 (1986) 106.

[8] M.J.R. Oliveira, Projeto Leste - Província Pegmatítica Oriental: Mapeamento geológico e cadastramento de recursos minerais da região leste de Minas Gerais, Relatório Conselheiro Pena / S. Gabriel da Palha, $1^{\text {a }}$ Ed., CPRM, Belo Horizonte, Brasil (2000) 10.

[9] H.A. Nalini, Caractérization des suites magmatiques néoprotérozoiques de la région de Conselheiro Pena et Galiléia, Minas Gerais, Brésil, Première édition, École Nationale Superière des Mines, Saint Etienne, France, Dr. 
Thesis (1997) 237.

[10] M.L.S.C. Chaves, R. Scholz, D. Atencio, Rev. Geociências 24 (2005) 143.

[11] R. Scholz, "Mineralogia fosfática do distrito pegmatítico de Conselheiro Pena, Minas Gerais", Dr., Instituto de Geociências, Universidade Federal de Minas Gerais, Belo
Horizonte, Brasil (2006) 98.

[12] P. Černy, Geoscience, Canada, 18 (1991) 49.

[13] R. Scholz, M.L.S.C. Chaves, K. Krambrock, Asociación Geológica Argentina 14 (2011) 193.

(Rec. 18/05/2015, Rev. 10/12/2015, 08/02/2016, Ac. 19/02/2016) 